\title{
ALIGNING PARTICIPATION WITH AUTHORSHIP
}

\section{INDEPENDENT TRANSMEDIA DOCUMENTARY PRODUCTION IN NORWAY}

\author{
Joakim Karlsen \\ Faculty of Computer Sciences \\ Østfold University College \\ Remmen \\ 1757 Halden \\ Norway \\ joakim.karlsen@hiof.no
}

\begin{abstract}
Incentives to develop non-fiction transmedia projects have recently challenged the work practices of independent documentary filmmakers in Norway. However, research on documentary films has only minimally captured the emerging practice of making non-fiction transmedia. Based on an interview study undertaken in 2012/2013 and reflections on contributing to a recent non-fiction transmedia project, I find that the emerging practice faces many of the same challenges as the participative documentary practice of the 1970s, mainly that the facilitation of audience participation requires a break from the broadcasting logic of independent documentary film work.
\end{abstract}

Keywords: non-fiction transmedia, independent documentary film, art worlds, practice, participative documentary

\section{Introduction}

The independent documentary film community in Norway is small and consists of a handful of companies, often set up around one or two lead creatives. There are mainly two sources of funding for these producers, the national broadcaster (NRK) and the Norwegian Film Institute (NFI), and these institutions to a large degree define the who, what and when of independent documentary production in Norway. During the winter of 2011/2012, NFI encouraged independent documentary film producers in Norway to explore non-fiction transmedia, or 'audio visual documentary projects that are not film'. ${ }^{1}$ They arranged a series of workshops and seminars and opened their funding scheme to multi-platform documentaries. Since this initiative was taken by NFI, a couple of projects were been funded in 2012. The first one was Project Moken (2012), ${ }^{2}$ http://projectmoken.com, and shortly after this, the project 17000 Islands (2013) ${ }^{3}$ received substantial funding to develop an online tool for 'sculptural editing', http://17000islandsinteractive.com/ (Works in 
Chrome only). After these projects were funded, the NFI did not receive any further applications for the funding of any larger non-fiction transmedia projects. ${ }^{4}$

\section{THE PROJECT MOKEN UNIVERSE}

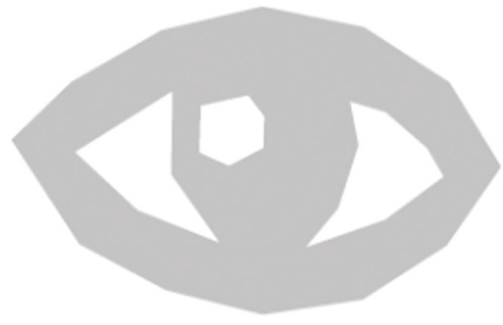

Documentaries

At the heart of Project Moken there is

a feature length documentary

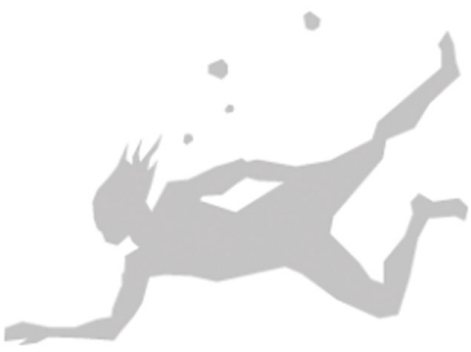

Hold your breath

Experience the underwater realm of the Moken.

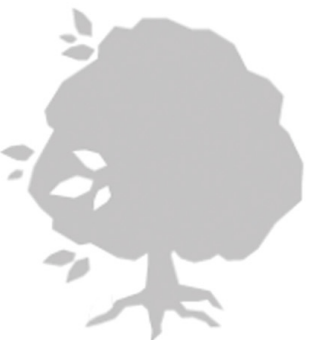

The tree campaign

One Tree can save the Moken culture!

Click here to find out how and be part of it!

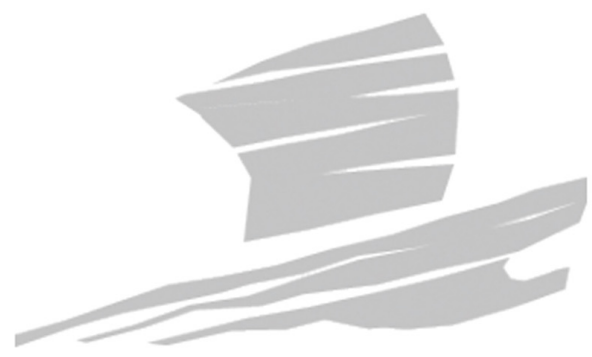

The Ocean as a place

For the Moken, the ocean is a place

not a barrier.

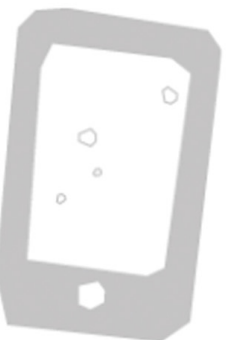

The Moken App

Be a free-diver! Hold your breath along with a Moken - renowned for their natural free-diving skills.

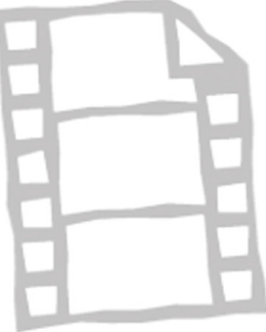

\section{Moving Footage}

Access our library of short

documentary clips and edited

reseach. Comments

Project 1: The transmedia components of the Moken Project.

The main contribution of this article is to describe empirically some of the practices of making non-fiction transmedia in Norway in the years 2012 to 2013. It specifically addresses how facilitating for audience participation has challenged earlier practices of making independent documentary films in this context. The findings presented in this article are most likely relevant for research on similar developments in the Nordic countries and parts of Europe, where government institutions and public service broadcasters play an important role in the funding of independent documentary film projects. The established bureaucratic practices of these institutions are set up to support traditional documentary film production, and they will need to be adapted to accommodate for new forms of documentary afforded by new media technologies.

In the following, I will review relevant literature on emerging forms of documentary and address how these forms have the potential to reconfigure the relationship between author and audience established in the documentary film tradition. I will then develop a perspective on documentary practice that provides a framework for understanding if and how the making of non-fiction transmedia is misaligned with earlier documentary film practices. Thereafter, I will summarise the 


\subsection{ISLANDS}

an interactive experiment in documentary image making

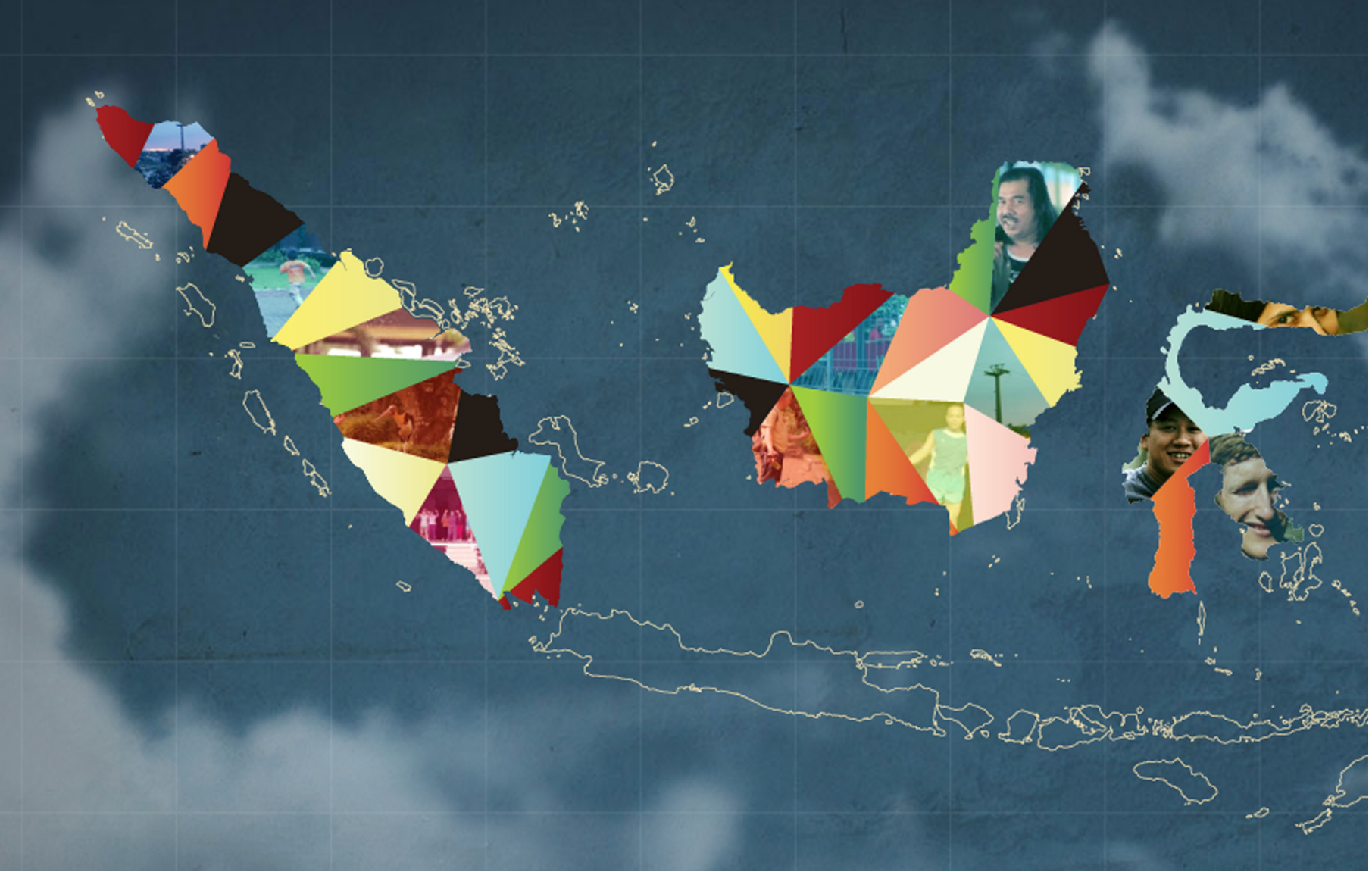

Project 1: The landing page of the project 17000 Islands, affording the possibility of 'sculptural editing'.

findings from an interview study with independent documentary producers in Norway undertaken in 2012/2013 and from participating in a non-fiction transmedia project, where I contributed as a full member. In the discussion, I will highlight the implications of these findings for independent documentary film practitioners wanting to make non-fiction transmedia and for the institutions aiming to support them.

\subsection{Authorship, Audience Participation and Art Worlds}

A taxonomy of documentary forms being developed with new media technologies would reveal great variation. New types of non-fiction storytelling have emerged, where practitioners have experimented with new materials, tools and techniques for making and distributing documentaries. Researchers have attempted to define the emerging documentary forms, using concepts like interactive documentary, ${ }^{5}$ database documentary, ${ }^{6}$ web-documentary ${ }^{7}$ and

5 Dayna Galloway, Kenneth B McAlpine and Paul Harris, 'From Michael Moore to JFK Reloaded: Towards a Working Model of Interactive Documentary,' Journal of Media Practice, 8, 3, 2007, 325-339.

6 Hart Cohen, 'Database Documentary From Authorship to Authoring in Remediated/Remixed Documentary,' Culture Unbound: Journal of Current Cultural Research, 4, 2012, 327-346.

7 Siobhan O'Flynn, 'Documentary's Metamorphic Form: Webdoc, Interactive, Transmedia, Participatory and Beyond,' Studies in Documentary Film, $6,2,2012,141-157$. 
transmedia documentary, ${ }^{8}$ and have often focused on interactivity and/or audience participation in their definitions. Transmedia, as defined by Henry Jenkins, ${ }^{9}$ is a category of storytelling that belongs to a genealogy of creating content on several platforms associated with the same story universe. The audience engagement with the universe, across different media platforms, becomes the prime concern, and one example from fiction storytelling is the Matrix. ${ }^{10}$ However, the concept of transmedia, as used in the Norwegian context of independent documentary film production in 2011/2013, has taken on both a wider and narrower meaning than that conveyed in Jenkins' definition. It has included all types of documentary that are made to more than film and a more inclusive use of the term 'transmedia'. But with an emphasis on how audience activity should influence the contents of the documentary itself, it is a narrower use of the concept.

The understanding of these developments, expressing a local use of the concept of transmedia, will require a developed theory of audience participation. The documentary studies field has a strong tradition of studying authors, their works of art and how the documentary film form progresses and develops historically ${ }^{11}$. However, the emerging non-fiction transmedia documentary practice, as reported on in this article, has challenged this primacy of the author ${ }^{12}$ and of her work of art ${ }^{13}$ as well as the stable relationship between authorship and readership. ${ }^{14}$ Hart Cohen ${ }^{15}$ captures all three aspects when he claims that what he coins the 'database documentary' challenges the concept of 'auteur' because of how the database opens for interactivity and unpredictable readings. Sandra Gaudenzi, when writing about interactive and participative documentaries, claims that "...the role of the author has to move from "narrator of a story" to "facilitator of other people's stories"'. ${ }^{16}$ She uses Bill Nichols 'mode of documentary' as a starting point and proposes four 'modes of interactivity', ${ }^{17}$ with each mode expressing different ways in which authors place the audience/users in relation to technology when representing reality. Further, researchers have reconceptualised the author as a curator ${ }^{18}$ and not the least as a designer. ${ }^{19}$ These researchers have moved from an author centred understanding of documentary practice to an audience or user centred one.

When re-conceptualising the relationship between author and audience, Nico Carpentier ${ }^{20}$ is critical of deterministic simplifications of this relationship and uses the longer tradition of audience theory to resituate the debate historically with the main aim of salvaging a deep understanding of audience participation. He claims to see 'enthusiastic and sometimes messianistic discourses of novelty' when it comes to "new" media technologies and practices'. This perspective is similar to the shift from one-to-many to many-to-many communication as articulated by Jay Rosen, ${ }^{21}$ the re-articulation of the audience into the 'producer' as articulated by Axel Bruns ${ }^{22}$ and the convergence of top-down

8 Ibid.

9 Henry Jenkins, 'Confessions of an Aca/Fan: Archives: Transmedia Storytelling 101,' 8 December 2016, http://henryjenkins.org/2007/03/ transmedia_storytelling_101.html.

10 Henry Jenkins, Convergence Culture: Where Old and New Media Collide, New York University Press, 2008, p. 93.

11 Hart Cohen, 'Database Documentary: From Authorship to Authoring in Remediated/Remixed Documentary,' Culture Unbound: Journal of Current Cultural Research, 4, 17, 2012, 327-346.

12 Ibid.

13 Jonathan Dovey and Mandy Rose, '“This Great Mapping of Ourselves”-New Documentary Forms Online,' BFI Companion to Documentary, 2013, 366-375.

14 Nico Carpentier, 'Contextualising Author-Audience Convergences,' Cultural Studies, 25, 4-5, 2011, 517-533.

15 Cohen, 'Database Documentary,' 2012.

16 Sandra Gaudenzi, 'Strategies of Participation: The Who, What and When of Collaborative Documentaries,' in in Kate Nash, Craig High, and Catherine Summerhayes, eds, New Documentary Ecologies: Emerging Platforms, Practices and Discourses, 2014, pp. 129-148.

17 Sandra Gaudenzi, 'The Living Documentary: From Representing Reality to Co-creating Reality in Digital Interactive Documentary,' PhD Thesis, 2013.

18 Dovey and Rose, '“This Great Mapping of Ourselves”,' 2013.

19 Cohen, 'Database Documentary,' 2012; Sharon Daniel, 'Argument, Inquiry and Political Narrative: Navigating an Aesthetics of Database Documentary,' Database/Narrative/Archive, 2013; Jon Dovey, 'Documentary Ecosystems: Collaboration and Exploitation,' in Kate Nash, Craig High and Catherine Summerhayes, eds, New Documentary Ecologies: Emerging Platforms, Practices and Discourses, 2014.

20 Carpentier, 'Contextualising Author-Audience Convergences,' 2011.

21 Jay Rosen, 'Afterword: The People Formerly Known As the Audience,' Participation and Media Production: Critical Reflections on Content Creation, 2008, 163-165.

22 Axel Bruns, 'Produsage,' Proceedings of the 6th ACM SIGCHI Conference on Creativity \& Cognition, 2007, 99-106. 
business with bottom-up consumption and production practices as articulated by Henry Jenkins ${ }^{23}$ and Clay Shirkey. ${ }^{24}$ Important for the argument in this article, Carpentier claims that deep audience participation is not necessarily a consequence of new media technologies and uses the BBC project Video Nation (1993-) to recount how this project deteriorated when moved online http://www.bbc.co.uk/videonation/archive/. According to Carpentier, the participation that broadcasting logic facilitated was deeper and more effective than the participation enabled when going from compiled broadcasts to an online archive. He emphasises how the development of participative media must be seen in a longer historical perspective and that deep audience participation needs to be anchored in and protected by strong organisational structures.

The organisational framework of independent documentary production can be partially described by Nichols' concept of mode and his view of mode as depending on a community of practice, ${ }^{25}$ as well as by Howard S. Becker's theory of art worlds. ${ }^{26}$ Both scholars use practice theory ${ }^{27}$ to a certain degree when explaining the phenomena they study. They emphasise that the production of film and other forms of art is historically situated both socially and materially and is performed and re-performed as practice, constrained but not determined by its organisational structures. Becker describes the social embeddedness of art-how art is created in a system with a high degree of participation from all involved parties. He uses two main concepts, collective (cooperative) activities and conventions, to describe the art world. The collective (cooperative) activities, according to Becker, are ${ }^{28}$ as follows: 1) developing an idea about the kind of work and its form; 2) executing the idea with the help of materials and equipment; 3) manufacturing these items; which requires money; 4) the money is raised by distributing the artwork to an audience; 5) supporting activities are required for this process; 6) for the system to work or for an artwork to exist, it needs both appreciation and response from an audience; 7 ) the system depends on creating and maintaining a rationale for its existence. According to Becker, there are interdependencies and cooperative links in this system that are forged by mutual knowledge of and recognition of conventions. ${ }^{29}$ Conventions are what make cooperation possible among all actors, including the audience. ${ }^{30}$ According to Baker, an artist adapts to his audience, to ensure their appreciation, by relying on an intimate knowledge of the conventions relevant for the specific art form.

Applying Becker's theory of art worlds to frame and understand emerging documentary practices, as studied in this article, highlights the dilemmas and problems surfacing when developing a radically new practice within an existing art world. Transmedia non-fiction is an emerging and experimental art form, depending on new types of materials and equipment, lacking established means of distribution, with few stable sources of revenue, needing new kinds of support personnel like designers and programmers, seeking an appreciative and participating audience and with a need to align itself with the existing rationale of independent documentary film production. Further, the lack of well-established conventions for what transmedia non-fiction actually is can make the process of forging new cooperative links challenging. The studies reported on in this article exemplify some of these challenges. They focus on the difficulties with aligning audience participation with the current understanding of authorship, common in the independent documentary film community in Norway.

\section{Interviewing and Working with Independent Documentary Producers}

When studying practice, it is important to rely on observations and thick empirical descriptions that emphasise practice as situated, embodied and performed. Therefore, Davide Nicolini ${ }^{31}$ recommends participant observation when zooming

23 Jenkins, Convergence Culture, 2008.

24 Clay Shirky, Here Comes Everybody: How Change Happens When People Come Together, Penguin, 2009.

25 Bill Nichols, Representing Reality: Issues and Concepts in Documentary, Bloomington, 1991, p. 23.

26 Howard Saul Becker, Art Worlds, University of California Press, 1984; Hans van Maanen, How to Study Art Worlds : On the Societal Functioning of Aesthetic Values, Amsterdam University Press, 2009.

27 Davide Nicolini, Practice Theory, Work, and Organization: An Introduction, Oxford University Press, 2012.

28 Becker, Art Worlds, 1984, p. 2-4.

29 Ibid., p. 25.

30 Ibid., p. 29-30.

31 Nicolini, Practice Theory, Work, and Organization, 2012. 
in on the accomplishments of a practice. But when doing this, he writes, we as researchers needs to 'scrutinize two practices at the same time: our epistemic practice and what concerns us' ${ }^{32}$ In this study, I have relied on interviews but also on being a full member of several transmedia non-fiction projects. I have sought to scrutinise my own involvements and how they relate to the reported findings. This has involved taking on the basic hermeneutical and iterative stance of action-research, ${ }^{33}$ with constant questioning of my own role as a project participant and actively taking part in processes of change. My role as a co-practitioner in the project reported on here was possible because of my background as a documentary filmmaker and earlier collaboration with the director. According to Nicolini, ${ }^{34}$ interviews alone are not sufficient when understanding practice but can make sense together with fieldwork. In this study, interviews have been a good way of uncovering practitioners' attitudes and concerns towards a not yet established practice.

\subsection{Findings from the Interviews}

To find and select the independent producers for my interviews, I used several sources. First, I used NFl's information on grants given between November 2010 and November 2012. ${ }^{35}$ Second, I asked the Norwegian film and TV producers' association to name the most active independent documentary producers among its members. Lastly, I marked off the producers whom I knew had made non-fiction transmedia or were about to do so. When this list was compiled and sorted, I contacted the producers from the top of the list and managed to get interviews with 14 informants working for 11 companies. In addition, I interviewed the documentary production advisor for NFI at the time. The interview guide was semi structured and consisted of six open questions that focused on the informants' understanding of and experience with transmedia. When conducting the interviews in 2012/2013, most of the interviewees had not produced any transmedia documentaries, but they had many thoughts on what this new form implied when it came to their own practice. In fact, several of them had worked on proposals for and prototypes of transmedia projects. In the following, I will focus on findings that relate to the producer's attitudes towards renegotiating the author-audience relationship implied by their understanding of transmedia and how they viewed the development of transmedia in relation to the organisational support they had at the time.

Most of the producers I interviewed emphasised that non-fiction transmedia have the same purpose as traditional documentary film.

...I think anyone interested in telling non-fiction stories have a primary fascination with real people, real stories and real destinies, and want to convey these stories to increase understanding and expand the horizons of people. [...] and I believe this is the purpose with transmedia too. It's only a new tool to do the same (\#12).

Even if they saw non-fiction transmedia as having the same rationale as traditional documentary film, most of the producers emphasised that a transmedia documentary must involve and represent the audience as part of the story. Several producers framed this opening for audience participation as a strengthening of the utilitarian aspects of documentary by facilitating more engagement and increasing the potential for inducing real changes in society. These producers saw this as the strongest feature of transmedia documentaries, to open for a democratisation of documentary film.

This is a democratization of the film format [...] When the audience is drawn into, and take part in, building an opinion, an opportunity for having a say (\#6).

However, many of the producers were worried about how to keep editorial control when opening for audience contributions. How would they be able to steer what a documentary becomes, when the audience itself produces much

32 Ibid., p. 217.

33 Stephen Toulmin, Beyond Theory: Changing Organizations through Participation, John Benjamins Publishing Company, 1996.

34 Nicolini, Practice Theory, Work, and Organization, 2012, p. 217.

35 'Tilskuddsordninger for dokumentarfilm,' NFI, 8 December 2010, http://www.nfi.no/bransje/tildelinger/søkeresultat?

search=\&year=2010\&type=117638. 
or all the material? None of them liked the idea of letting a documentary project grow organically based on content created by the audience.

One could imagine that the audience contributed data into a database, but if it was like this instant producing, without any quality control, then I think that it would break with what we want to do (\#2).

Many of the producers therefore emphasised the unabated need for a clearly authored narrative, even when involving the audience. The participants from the audience should be given clearly defined roles in line with or contributing to a story controlled by the director. One of the producers gave a reason for this:

But the important thing that is difficult for us, is to open up for user participation. We resist this, because instinctively, we know that we have become what we have become because we tell stories to an audience, not that the audience tells stories to us (\#4).

When asked how they could facilitate for audience participation in a transmedia project, it became obvious that this was uncharted territory for most of the producers, although almost all of them would have liked to get this to work.

When it came to organisational support for making transmedia documentaries, several of the producers were not sure what NFI wanted to achieve with its initiative of supporting non-fiction transmedia. They said they would rather initiate such artistic priorities themselves, in cooperation with NFI's commissioning editors, and would have preferred a more bottom-up approach by their main funder. Further, several of the producers said they feared that transmedia projects would receive too much of the relatively small amount of government money earmarked for documentary production and called for a separate funding scheme. One of the producers had the perception that transmedia production would cost a lot of money and, because of this, wanted to protect what he called 'primary film production work':

It [transmedia] comes in the way of the primary work that we do which is storytelling for film and television. I hear about people who have done transmedia projects that are damn frustrated because they feel that money runs out... (\#13).

Several of the producers wanted to protect the existing documentary film practitioners and were sceptical about sharing the relatively limited funds available with practitioners with other backgrounds and skills. Further, some of the producers felt insecure about how to recruit skilled people and how to negotiate a proper price for their services.

... I know how to deal in the film world, but I do not know to deal with a programmer. I do not know what it costs (\#10).

They seemed to understand that they could alleviate this problem by buying transmedia components from advertising agencies and game development companies who have more experience with developing content for digital platforms. However, several of the them had already realised that they could not afford to buy finished products from these agencies with, in their view, an unreasonable overhead. As several of them mentioned, the only opportunity to hire skilled people they could afford was to find freelance workers who could help them solve clearly defined tasks.

...often it is important to define some core issues or core challenges and find someone specific who can set aside a few hours or days or weeks to the work, instead of hiring an agency who bills a lot of hours on miscellaneous things (\# 11).

When it came to planning transmedia documentary projects, most of the producers admitted that they had little experience and that they needed to do more transmedia projects to be able to gain confidence.

I do not think I know enough about that. If I am going to plan, fund and calculate the cost of doing a larger transmedia project, I will need to get some help, indeed (\#14). 
However, several of the producers believed that the independent documentary film community would learn quickly, and that most of them had sufficient knowledge of general project management to get by. One of the informants, who had some experience with transmedia production, said that the complexity of the projects had increased with transmedia and that this required a new mind-set to avoid making mistakes.

You cannot launch a mobile application where the graphics [are] poorly linked to the code underneath and where functions are buggy. [...] I think that if you go in with a traditional television production mind-set when creating transmedia, you'll get some nasty surprises (\# 8).

\subsection{Findings from Doing Project Work}

In parallel with and after conducting the interviews, I worked with the director and producer of the documentary film Our daily bread (2013) to create transmedia content related to the film. We experienced some nasty surprises, as referred to by the last informant cited in the previous chapter, but I believe this had to do with more than a specific mind-set. We had several setbacks that exposed the challenges of creating non-fiction transmedia in this context. We chose two very different approaches for the project. The first was to work with NFI to get support for a full non-fiction transmedia project. When this failed, we devised a simpler bottom-up strategy of making a working prototype of a mobile crowdsourcing application, hoping that a tangible outcome could convince funders to support the project.

The film, which was the main component of the project, had been commissioned jointly by NRK and NFI some time before I became involved in the transmedia development work. The film was in production when I joined the project, and the topic was Norwegian food-policies and how centralisation and monopolistic tendencies in the national food market give consumers fewer choices, poorer quality and higher prices than would otherwise be the case. The first undertaking in the transmedia part of the project was to write an application for additional funding from NFI, where the full transmedia project was defined. The work was divided between the producer, the director and me. As a starting point, I defined a project template, combining the traditional documentary film concept template with Tim Pratten's transmedia template, ${ }^{36}$ a template developed for writing video game concepts ${ }^{37}$ and a general template for digital storytelling concepts. ${ }^{38}$ The director and I wrote most of the application, and the producer set up a budget and plan for the project. We proposed to build a webpage on a spatial metaphor of a local grocery store. The different areas of the store, and its shelves, would link to information about different aspects of the Norwegian food business. Further, we wanted to build a mobile application using real stores as an interface to a subset of the same information. We described how the audience could interact with information via their smartphones in the store, using barcodes as a main reference. Lastly, we proposed to arrange events where users of the webpage, the mobile application and the film could meet up for debates, lectures and other food policy related calls, before, during and after the film was broadcasted on television. The application, with a budget of $\$ 100,000$, was rejected by the NFI. Little feedback was given, so it is difficult to know the real reasons behind the rejection. It could concern a lack of resources, internal politics, artistic evaluation, portfolio considerations, strategic concerns or the unfamiliarity of the project template. The positive finding from this experiment was that working out a new project template afforded the producer, director and me to reach a common understanding of what a non-fiction transmedia project was, early in the process.

Some time after this, the producer allocated some minor funds to the project, and in spring 2013, after a period of mainly conceptual work, we developed a prototype of a map-based mobile application called 'My Store'. With the help of one of my students, who worked part time on the project, and a graphic designer, we made a mobile web application with the basic functionality to find and select a store on a map and share text, images and video to it. The working prototype, with bugs and all, is available for exploration at http://itp.hiof.no. This is a copy of the project and can be freely used by the readers of this article, preferably from a mobile phone. The three screen shots below show the splash screen, the

36 Robert Pratten, 'Zen Films: Transmedia Workflow,' 8 December 2010, http://zenfilms.typepad.com/zen_films/2010/06/transmedia-workflow.html.

37 Flint Dille, The Ultimate Guide to Video Game Writing and Design, Lone Eagle, 2006.

38 Carolyn Handler Miller, Digital Storytelling: A Creator's Guide to Interactive Entertainment, Focal Press, 2008. 
find store on the map screen and lastly the screen where you can watch what other people have uploaded and contribute text, images or videos yourself.

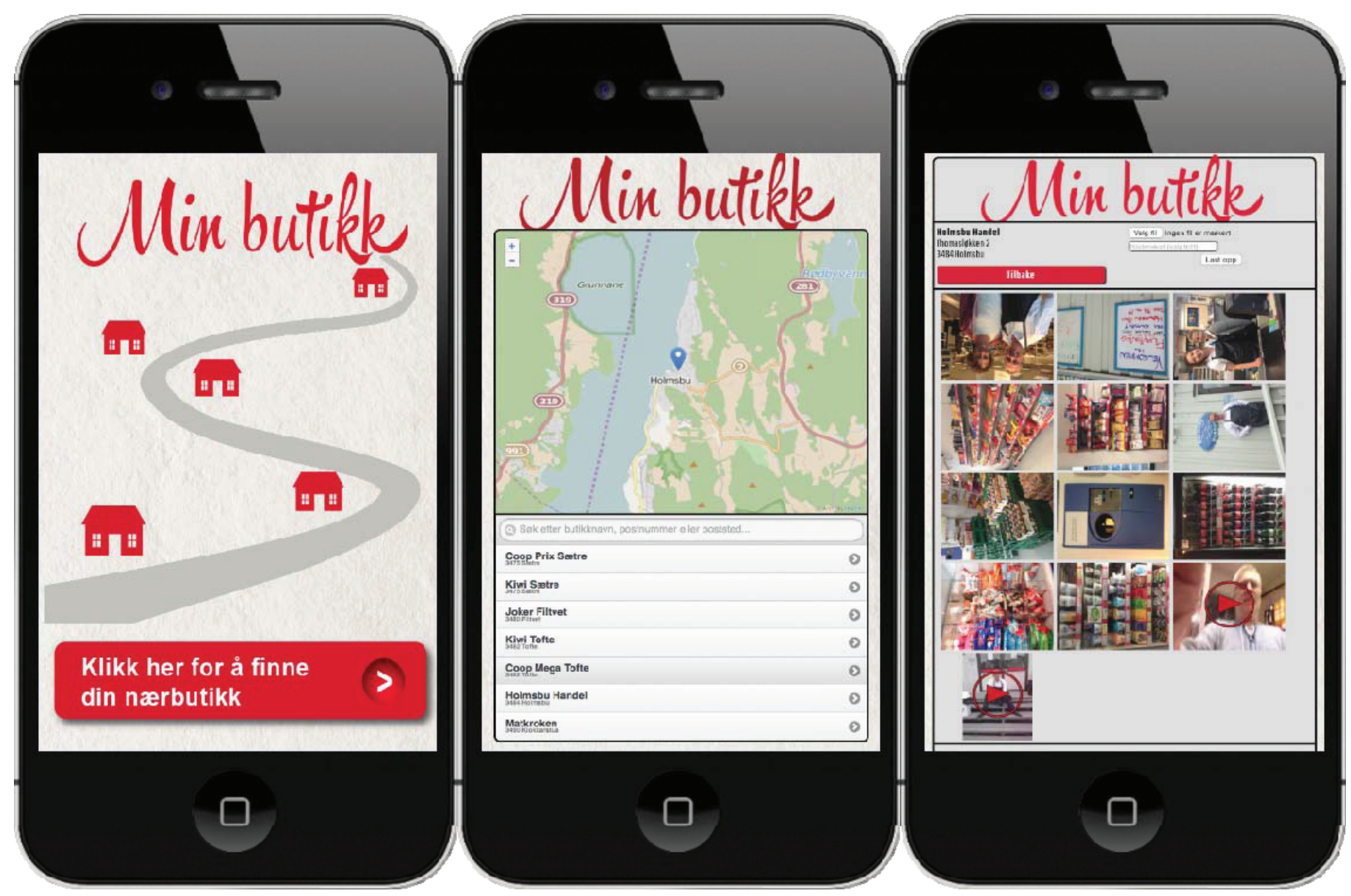

Prototype 1: Screenshots showing the main pages of the app enabling the sharing of text, images and video to a local store.

We tested the prototype as part of a local showing of the film in the small town where the main character, an owner of a small grocery store, lived. To get people to discover and use the application, we visited the community some days in advance and gave a talk about the project in a local elementary school (11-12 year olds). While there, we recruited two participants and made an appointment with them to meet us at the store after school. In the meantime, we visited several stores in the area and randomly selected people to use the mobile application (with a little help). We thought that some genuine videos would increase the likelihood that people would contribute later. When the kids tested the mobile application at the store, a journalist from the local newspaper visited. The local screening of the film and the piece in the newspaper were on the same day, and the attendance was good. As part of the programme, I introduced the app and demonstrated its use on a large screen. In our view, we had done everything we could to ensure that we were going to get a positive result from the experiment, but during the next couple of days, no contributions were made by the townspeople.

\section{Aligning Audience Centred with Author Centred Practices}

Making non-fiction transmedia within the existing art world of independent documentary film production in Norway led to breakdowns that exposed some issues with aligning the emerging practice with the old. Facilitating for audience 
participation led to issues concerning how to negotiate a fitting project model, how to legitimise non-fiction transmedia as a work of art and problems with adapting the scope of a non-fiction transmedia project to the broadcasting logic of independent documentary film production.

The first issue of devising a fitting project model was to adapt the traditional linear approach of traditional film making to include the necessities of iterative design. This involved finding user requirements, developing alternatives, prototyping and evaluation. ${ }^{39}$ At the start of the project, when writing the application to NFI, we wrote transmedia content as we would have written for film. We authored the first concept document using ideas and material that were available to us at that time, with little involvement from representatives of the audience or other stakeholders. Even if I had some experience with design work and knew that we should have devised a more user driven process to establish requirements, the focus on getting the first money got the upper hand. Basic insights from user oriented design or interaction design could have helped us to devise a plan that involved real users and stakeholders from the start. This would probably have given more ideas, better ideas and not the least ideas that would have a better chance of being supported later in the process.

In the second phase of the project, we chose an approach that is much closer to what is common in a design project, making and evaluating a prototype. As most designers know, working with an iterative project model, is that a prototypes value lies in its evaluation, and a failed prototype can lead to the biggest improvements in the next iteration of the project. Taking on a design perspective, I therefore believe the prototype 'my store' was partially successful. The trial uncovered some fundamental problems and possibilities with the prototype, concerning people's ability and willingness to contribute. However, in this project, the result was seen as a failure. I believe this to be a consequence of how the experiment was framed, the role it was conceived to have in the larger project. Creating a prototype and conducting field tests are 'new' activities in a documentary project, but it was quickly framed as making a pilot. The main purpose of a pilot is to release funds for producing the documentary film, and the reason we made the prototype 'my store' was to materialise and document how transmedia could work well to convince NFI and NRK to support the project. When we did not receive any contributions from people when trying it out, the prototype's value as a pilot was insignificant.

The interviews seem to support this conflict between an iterative design logic and the more linear film production logic. The main issue when it came to a project model was how most of the producers were highly confident that they would be able to plan transmedia projects well. They simplified the problem so that the focus was on hiring the right people, to the right price or, alternatively, to buy whole solutions from agencies and consultants. Understandably, they framed this more within a linear manufacturing logic than an iterative one. Most of the practitioners I interviewed had limited experience with the many facets of attracting and engaging an audience on several platforms. They will need to obtain first-hand experience in making mobile applications, mini-games and multimedia to be able to see how a user-driven iterative project model could be a better fit than an author-driven linear model for this kind of work.

The second issue of legitimising an indeterminate work of art, with an uncertain moment of appreciation, is real when it comes to non-fiction transmedia. In the Norwegian context, the main event for a documentary filmmaker is when the film is either screened at a cinema or broadcast on television. This is the moment of appreciation that is the main concern for all involved stakeholders in this particular art world, including its funders. Before a new 'model of appreciation' is in place for non-fiction transmedia, with a more inclusive definition of what counts as an audience, it is probably going to be difficult to finance these projects, as we experienced when working on funding the transmedia components of Our daily bread (2013).

The interview with the production advisor at NFI provided insight in regard to the dilemmas that surface when funders seek to adapt a bureaucratic practice so that the innovation of new types of documentaries fall within their given mandate. According to the advisor, a good non-fiction transmedia project should have a strong audio-visual form (important in the mandate for the fund) and, at the same time, give the audience the ability to influence the story of the documentary itself. He used amateur sports as an example (orienteering), and claimed that an event, open to the 
audience, taped, edited and screened, was transmedia, which makes little sense in this context. Any filmed events, without strict control of who is participating, would become transmedia. To be able to open up for transmedia, NFI would need to reconsider its current criteria for awarding projects and make them more platform neutral and less dependent on a strong narrative supported by audio-visuals. From the interviews, it seems that there is a high degree of continuity between the old and new practices when it comes to purpose. Documentary film practice and non-fiction transmedia practice, as understood by the interviewees, share the same concern for giving people a voice and for contributing to the creation of an engaged public around important issues in society. This insight can be a promising starting point for defining criteria that are oriented towards the value system of the independent film documentary community, but that includes indeterminate audience-driven documentary forms as legitimate works of art.

The third issue that surfaced mainly in the project work was aligning the spatial and temporal scope inherent when making transmedia, with the broadcasting logic of independent documentary film production. The traditional understanding of authorship in documentary film implies a specific audience model. When Seymour Chatman ${ }^{40}$ describe the narrative situation, the reader is framed as the 'implied reader', pointing to the fact that an author needs to establish and maintain a working model of her readership, translated to our context, of her audience. According to Elefante and Deuze, ${ }^{41}$ this ability to work with 'audience-in-their-heads' and use this mental model to make creative decisions is important for creative workers. For our purposes, this can be reframed as a 'public service mind-set' that delineates a narrative situation that is general and non-specific, reaching out to anyone and no-one in particular. We adopted this mind-set when working with the transmedia concept and when designing and evaluating the prototype, entertaining a mental model of our audience as Norwegians in general. In combination with this, we worked with the temporal scope of a relatively large but short media event, i.e. the prime-time screening of the film on NRK. But how is it possible to design and evaluate a prototype, seen as a part of this kind of media logic, when it is impossible to simulate the media event beforehand? It is highly unpredictable and challenging to design for big media events due to how they feed into the larger media output, and how audiences choose to respond to them.

The general audience model, with a wide scope geographically and a narrow scope temporarily, is probably the opposite of the strength of transmedia: long term engagement with smaller communities around specific issues. This scope is comparable to what the participatory video movement in the 70 s worked with, ${ }^{42}$ when the affordances of video technology as compared to film opened for new production practices, emphasising 'process, not product'. Stephanie Tripp ${ }^{43}$ explains how members of the People's Video Theatre (PVT) movement covered public events and interviewed people whom they invited:

...to visit the group's loft in the West Village to watch the videos and discuss them. Screenings were open to the public; a flyer for one of PVT's weekend shows invited prospective attendees to "see mini documentaries,"

"speak back to the news," "become part of the news," and "see yourself" (qtd. in Shamberg and Raindance, 'Official Manual' 18).

PVT engaged with political controversies and interviewed stakeholders 'as a method of mediating (literally) disputes', with a distribution model 'centered on community-based participation and decision making'. Tripp uses her story of PVT and other participatory video movements to draw attention to how today's citizen journalists and YouTubers face the same challenges as the early pioneers. This study seems to indicate that the same is true for practitioners making nonfiction transmedia.

40 Seymour Chatman, Story and Discourse: Narrative Structure in Fiction and Film, Cornell University Press, 1980.

41 Phoebe Harris Elefante and Mark Deuze, 'Media Work, Career Management, and Professional Identity: Living Labour Precarity,' Northern Lights: Film \& Media Studies Yearbook, 10, 1, 2012, 9-24.

42 Stephanie Tripp, 'From TVTV to YouTube: A Genealogy of Participatory Practices in Video,' Journal of Film and Video, 64, 1, $2012,5-16$.

43 Ibid. 


\section{Concluding Remarks}

In this article, I have given an account of how the independent documentary community in Norway received and reacted to NFI's initiative in 2012/ 2013 to explore non-fiction transmedia. The interviews revealed that the producers were able to align the purpose of making transmedia with their current practice but did not like the idea of losing editorial control. The producers had problems with articulating how the audience could participate and how participation could be facilitated for within their existing linear project model.

The experience of working with developing transmedia has emphasised certain issues with adapting transmedia work to fit in a documentary film project. First, the linear, product and story oriented project model of independent documentary film production was unfitting. The iterative, experimental approach, arguably a better fit for this kind of project, was sidestepped by the heavy emphasis on producing concepts and pilots that could release additional funding. Second, what counted as a work of art, as codified in NFI's bureaucratic practice, failed to resolve what the nature of our project was. A utility-oriented redefinition of funding criteria, focusing on platform neutrality and a wider definition of legitimate documentary forms, could have alleviated this problem. Lastly, this to a large degree came down to the core concern of aligning participation with a working model of authorship. The current scope of the 'public service mind-set' is geographically wide and temporarily narrow, which is perhaps the opposite of what makes sense when building communities around societal issues.

As noted in the introduction, there have been no major applications to NFI for funding non-fiction transmedia after the initial flurry in $2011 / 2013$. This does not necessarily mean that there are no projects being developed; rather, it means that independent documentary producers have not seen any reasons to add transmedia components when applying to NFI for money. The reason for this could be that the initial definitional and bureaucratic problems have created uncertainties of what counts as a legitimate non-fiction transmedia contribution. Another plausible explanation is that the independent documentary film practice in Norway has established a stable art world that will reproduce itself and change more slowly than NFI anticipated in 2011. The practitioners rely on the well-established author-work-audience model of documentary film that is tightly coupled with an 'audience-in-their-heads' approach and the logic of public service broadcasting.

If one understands non-fiction transmedia as a continuation and a strengthening of independent documentary film as a participatory practice, it is possible to use the fate of the participatory video movement of the 70s to explain the seemingly low appetite for experimentation with non-fiction transmedia in Norway recently. The participatory video movement of the 70 s has continued to be marginal, ${ }^{44}$ underlining incompatibilities between a practice centred primarily on audience participation and the mainstream documentary film practice centred on authorship. This, to follow Carpentier, ${ }^{45}$ indicates that facilitating for deep audience participation has less to do with new media technologies than the underlying organisational support. To use Becker's theory of art worlds, considering the importance of the conventional art works of documentary film and the rituals surrounding its distribution and appreciation, it seems more likely that the non-fiction transmedia documentary, which is no longer film, will generate an art world of its own.

\section{Biography}

Joakim Karlsen has worked with documentary film and television from 1994 to 2000 as director and editor. He has studied computer science, media and design, and from 2008 he has worked as an assistant professor at Department of Computer Science, Østfold University College. He is currently a PhD Candidate at the department of Informatics, University in Oslo, writing a thesis on documentary, journalism and and new media technologies.

44 Ibid.

45 Carpentier, 'Contextualising Author-Audience Convergences,' 2011.

VIEW Journal of European Television History and Culture Vol. 5, 10, 2016 DOI: 10.18146/2213-0969.2016. jethc111 Publisher: Netherlands Institute for Sound and Vision in collaboration with Utrecht University, University of Luxembourg and Royal Holloway University of London. Copyright: The text of this article has been published under a Creative Commons Attribution-Noncommercial-No Derivative Works 3.0 Netherlands License. This license does not apply to the media referenced in the article, which is subject to the individual rights owner's terms. 